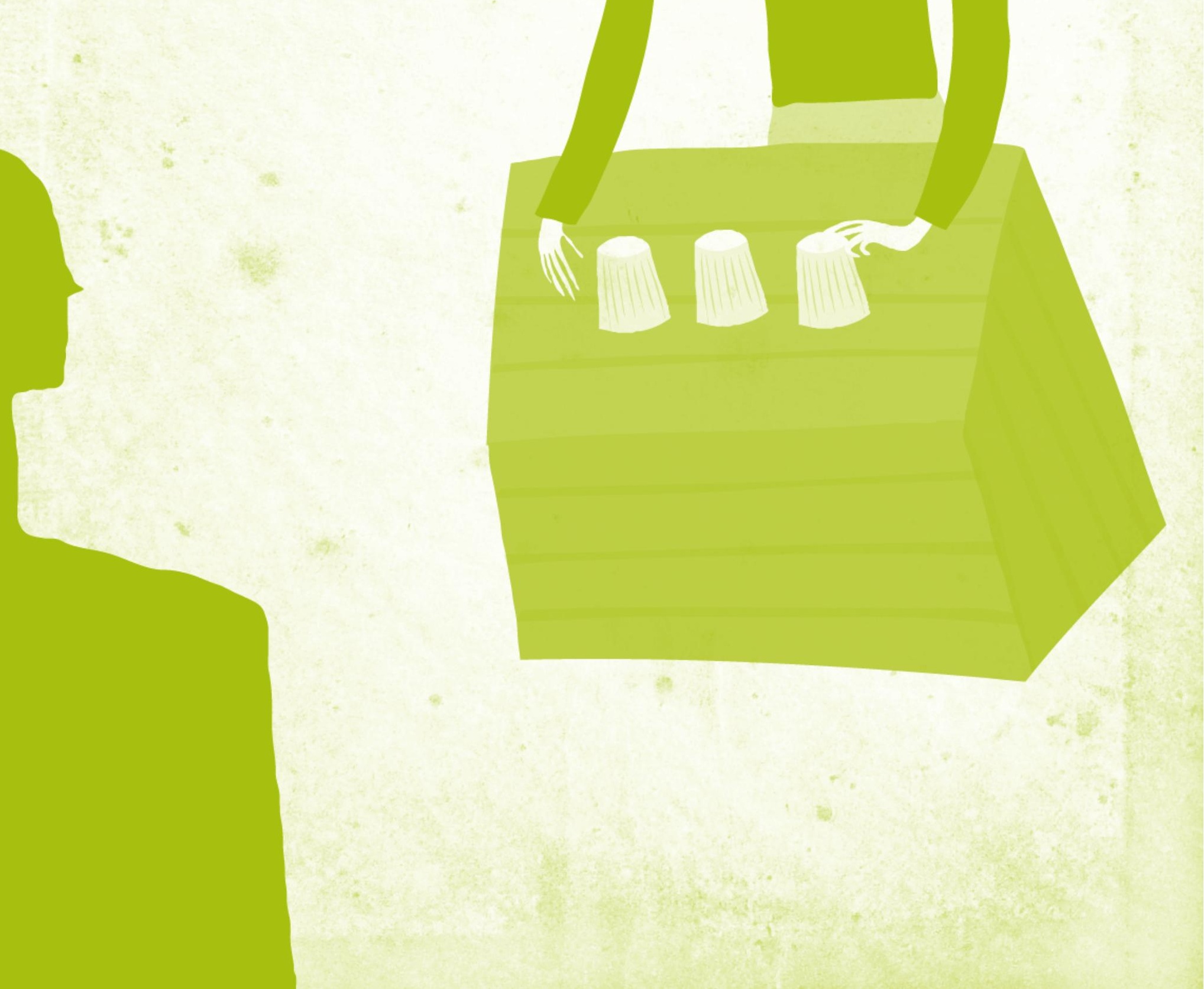




\section{Um triângulo da marca para evitar a branding myopia: contribuição semiótica para um modelo integrado de compreensão da marca}

Paulo de Lencastre

- Doutor em Ciências Econômicas Aplicadas pela Universidade Católica de Lovaina (Bélgica)

- Professor de Marketing na Faculdade de Economia e Gestão da Universidade Católica Portuguesa

- Professor Convidado da Faculdade de Economia da Universidade do Porto, do Instituto Superior de Ciências do Trabalho e da Empresa (ISCTE), Lisboa, e da Escola de Comunicações e Artes da Universidade de São Paulo (ECA-USP)

- Organizador e co-autor de 0 livro da marca (Lisboa: Dom Quixote, 2007) e de Os horizontes do marketing (Lisboa e São Paulo: Verbo, 2000)

- Fundador e sócio da Bzzzbrand Consultants, Portugal

- plencastre@porto.ucp.pt

Ana Côrte-Real

- Doutora em Marketing pelo Instituto Superior de Ciências do Trabalho e da Empresa (ISCTE), Lisboa

- Professora de Marketing na Faculdade de Economia e na Escola Superior de Comunicação da Universidade do Porto

- Professora Convidada da Faculdade Economia e Gestão da Universidade Católica Portuguesa

- Co-autora de 0 livro da marca (Lisboa: Dom Quixote, 2007)

- Fundadora e diretora geral da Bzzzbrand Consultants, Portugal

- abeirao@fep.up.pt 


\section{Resumo}

Este artigo parte da metáfora da miopia para explicar a visão mais limitada da marca, entendida como o sinal de identidade de um produto. Sendo a marca um sinal, recorre à semiótica, a ciência dos sinais, para aplicar um modelo que alarga o conceito de marca a três dimensões: a do sinal de identidade propriamente dito; a do objeto a que o sinal se refere; e a da resposta do mercado ao sinal.

PALAVRAS-CHAVE: MARCA • BRANDING (GESTÃO DA MARCA) • SEMIÓTICA • MARKETING • MARKETING MIX • PRODUCT MIX • IDENTITY MIX • BRAND MIX • PUBLIC MIX • RESPONSE MIX • IDENTIDADE CORPORATIVA • EXTENSÃO DE MARCA • POSICIONAMENTO DA MARCA • IMAGEM DA MARCA • VALOR DA MARCA

\section{Abstract}

This article uses the short-sightedness metaphor to explain the more limited vision of the brand, understood to be the sign of identity of a product. As the brand is a sign, it resorts to semiotics, the science of signs, to apply a model that expands the concept of brand to three dimensions: the sign of identity per se; the object to which the sign relates; and the market's response to the sign.

KEYWORDS: BRAND • BRANDING • SEMIOTICS • MARKETING • MARKETING MIX • PRODUCT MIX • IDENTITY MIX • BRAND MIX • PUBLIC MIX • RESPONSE MIX • CORPORATE IDENTITY • BRAND EXTENSION • BRAND POSITIONING • BRAND IMAGE • BRAND EQUITY

\section{Resumen}

Se parte de la metáfora de la miopía para explicar la visión más limitada de la marca, entendida como una señal de identidad de un producto. Siendo la marca una señal, recurre a la semiótica, la ciencia de las señales, para aplicar un modelo que amplía el concepto de marca a tres dimensiones: la de la señal de identidad propiamente dicha; la del objeto al que la señal se refiere, y la de la respuesta del mercado a la señal.

PALABRAS CLAVE: MARCA • BRANDING (GESTIÓN DE MARCA) • SEMIÓTICA • MARKETING • MARKETING MIX • PRODUCT MIX • IDENTITY MIX • BRAND MIX • PUBLIC MIX • RESPONSE MIX • IDENTIDAD CORPORATIVA • EXTENSIÓN DE LA MARCA • POSICIONAMIENTO DE LA MARCA • IMAGEN DE LA MARCA • VALOR DE LA MARCA 


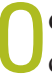
conceito de marca, praticamente acessório na literatura de marketing até finais dos anos 80 do século passado, passou a ser um conceito central a partir dos anos 90. Hoje proliferam livros e artigos sobre branding (gestão da marca), mas a integração do conceito no edifício conceptual do marketing ainda não está sedimentada.

O objectivo deste artigo é de, valendo-nos do edifício conceptual que o marketing moderno foi estruturando ao longo dos últimos 50 anos - com ponto de partida no artigo seminal de Levitt - Marketing myopia (1960) -, verificar como a marca lhe foi sendo incorporada. E procurar, com base nessa análise, propor um modelo de marca que contribua para a organização do conceito e sua integração no marketing.

\section{Branding myopia}

Tomemos como caso a Europa. Num país da União Européia, e até há bem pouco tempo, a definição jurídica de marca podia ser do tipo

"sinal ou conjunto de sinais nominativos, figurativos ou emblemáticos que aplicados por qualquer forma num produto ou no seu invólucro ofaçam distinguir de outros idênticos ou semelhantes." - exemplo de Portugal, Lei de Propriedade Industrial (ROCHA, 1991, p. 8)

Em 1994 a União Européia regulamentava finalmente a marca, estabelecendo uma ordem jurídica comum a todos os estados membros (MENDES, 2007). A definição de marca adoptada foi

"todos os sinais que possam ser objecto de uma representação gráfica, nomeadamente palavras, incluindo nomes de pessoas, desenhos, letras, números, a forma do produto ou a sua embalagem, desde que tenham capacidade de distinguir os produtos e serviços de uma empresa dos de outras empresas." (COMUNIDADE EUROPÉIA, 1994, p.1)1

Vemos nessa evolução da definição jurídica a passagem de uma visão da marca como sinal identificador de um produto singular e tangível - se não fosse tangível não seria susceptível de lhe ser "aplicado" o sinal da marca - para a visão mais abrangente da marca como sinal identificador de uma oferta, singular ou plural, de produtos e serviços.

1 Na definição brasileira, prevista na Lei da Propriedade Industrial de 1996 em vigor, o produto é assumido no singular: "marca é todo sinal capaz de identificar um produto ou serviço, distinguindo-o de outros de igual natureza" (DELBOUX, 2007, p. 106). 
UM TRIÂNGULO DA MARCA PARA EVITAR A BRANDING MYOPIA: CONTRIBUIÇÃO SEMIÓTICA PARA UM MODELO

INTEGRADO DE COMPREENSÃO DA MARCA • PAULO DE LENCASTRE • ANA CÔRTE-REAL

É verdade que no campo do marketing a visão da marca nunca foi tão míope como a das primeiras definições jurídicas. Socorramo-nos da mais divulgada definição de marca, proposta em 1960 pela American Marketing Association, e presente ainda hoje na maior parte dos manuais de marketing: "um nome, um termo, um sinal, um desenho, ou uma combinação destes elementos, com vista a identificar os produtos e serviços de um vendedor, ou de um grupo de vendedores, e a diferenciá-los dos concorrentes." (ALEXANDER, 1960, p. 8)

\section{Label branding myopia}

O conceito de marca, aplicável não só a produtos como estipulava o direito das marcas nos seus primórdios, mas também a serviços, corrige a primeira e mais rudimentar forma de miopia da marca. Vamos denominá-la, por simplicidade, de label myopia (miopia do rótulo). Com ela o branding restringe-se à criação e gestão de sinais gráficos apostos no produto tangível para o identificar distintivamente dos produtos semelhantes da concorrência.

Na prática da criação de uma identidade, a miopia do rótulo é darmos ao nosso novo produto ou atividade um nome bem evocativo de como ele é feito (Coca-Cola, folhas de coca e noz de cola) e um logotipo... bem desenhado (à época, quem desenhava melhor na empresa era o contabilista!).

\section{Product branding myopia}

No entanto, a definição tradicional de marca dos manuais de marketing não erradicou uma outra forma de miopia, que podemos designar, para distinguir da anterior, por product myopia (miopia do produto). Independentemente de se tratar de um produto ou serviço, a miopia do produto vê a marca como parte do produto, uma das variáveis do clássico marketing mix (KOTLER, 1967).

Devemos aqui ter consciência de que o conceito de produto em marketing foi revolucionado por Levitt (1960), inspirador da metáfora da miopia que agora aplicamos ao branding. Depois de Levitt, o produto passou a ser, antes de tudo, um benefício e, só depois, a sua tangibilização numa tecnologia que o suporta - não vendamos brocas, vendamos furos! A tecnologia passa, o benefício fica.

A gravidade da product branding myopia é do mesmo tipo. Os produtos passam, a marca fica. É redutor associar a marca a um produto específico e ao seu ciclo de vida, mesmo que tenhamos já desse produto a visão ampliada do marketing - lembremo-nos da Volkswagen e do seu produto fundador, o Fusca. 


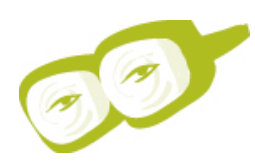

Sofrer de product branding myopia é pensarmos que sempre que criamos um produto novo lhe devemos dar uma nova identidade. Era como se a Volkswagen, quando quis ampliar a sua gama de automóveis, achasse que o seu nome (carro do povo) não servia para identificar e caucionar as aspirações topo de linha da empresa.

\section{Customer branding myopia}

Temos finalmente um terceiro tipo de miopia, a que ainda hoje domina os grandes manuais de branding (KELLER, 2008), e que designaremos por customer myopia (miopia do cliente). Trata-se de olhar para a marca na perspectiva da relação vendedor vs. cliente, esquecendo que a atividade da marca não se restringe a produtos e clientes, mas à pluralidade das relações de troca da organização com os seus públicos.

Se o objeto da marca não forem apenas os seus produtos para venda, mas todas as trocas que se fazem em nome da marca com os seus diferentes públicos, temos uma visão mais abrangente da marca, uma visão não míope, uma saudável visão global da marca.

Convém estar consciente de que corrigir a customer branding myopia não é apenas olhar para a marca como o sinal diferenciador da organização ou, pior ainda, como o seu rótulo gráfico. Seria corrigir uma miopia caindo nas duas restantes, incorrendo no vício grave de restringir a marca à gestão criativa da identidade visual, alheia à história e ao contexto da marca. Não é a organização que tem uma marca, é a marca que, em cada momento, tem uma organização que a suporta.

Marcas como a Coca-Cola (um remédio com cocaína!) ou a Volkswagen (o carro de guerra de Hitler!!!) teriam sofrido gravemente de customer branding myopia se, nos momentos de inflexão da sua história, tivessem decidido mudar de identidade porque o olhar do cliente sobre elas tinha que mudar. Teriam sido curiosos exercícios de marketing clássico. Mas provavelmente não estariam no galeria de honra dos sinais que a cultura do século XX lhes reservou.

Ao abordarmos a partir de agora a marca na perspectiva da semiótica, procuramos um modelo descritivo que represente esta visão oolítica em que a marca não é ape- 
UM TRIÂNGULO DA MARCA PARA EVITAR A BRANDING MYOPIA: CONTRIBUIÇÃO SEMIÓTICA PARA UM MODELO

INTEGRADO DE COMPREENSÃO DA MARCA • PAULO DE LENCASTRE • ANA CÔRTE-REAL

nas um rótulo, não é apenas um produto ou uma organização, não é apenas os seus clientes ou stakeholders: é a interação de todos eles. Como qualquer sinal, é complexa na teia de relações que gera entre elementos componentes. É simples se analisada à luz de uma sedimentada teoria dos sinais.

\section{Semiótica da marca}

Ao longo do seu desenvolvimento, a semiótica tem vivido partilhada entre duas grandes tradições de concepção e de pesquisa:

- a tradição "saussuriana" - do linguista suíço Saussure (1857-1913), que criou os fundamentos teóricos de uma ciência dos sinais. Para Saussure, a semiótica é uma extensão da linguística, já que a língua é um sistema de sinais que exprimem idéias. Qualquer sinal, linguístico ou outro, é, assim, uma entidade diádica composta por um significante - a forma do sinal, a sua expressão - e por um significado - o seu conteúdo (SAUSSURE, 19151966);

- a tradição "peirceana" - do filósofo americano Peirce (1839-1914), que desenvolveu uma concepção positivista do sinal, estudando-o na perspectiva da sua ligação com o mundo real. Para Peirce, o sinal é uma entidade triádica, incluindo como terceiro termo um referente do mundo real, que autoriza o estabelecimento de uma relação entre o significante e o significado (PEIRCE, 1931-1958).

A aplicação da semiótica ao marketing, com as primeiras abordagens a datar dos anos 80 (MICK, 1986), tem também vivido partilhada entre essas duas correntes. Pela nossa parte, pensamos que não devem ser encaradas como mutuamente exclusivas. No caso da marca, se pretendêssemos analisá-la apenas como sinal em si (um nome, um logotipo), independentemente dos produtos e ações de marketing que lhe possam estar subjacentes, nesse caso optaríamos pela abordagem diádica. É o que acontece quando se pesquisa a competência significante dos sinais usados como marca (FLOCH, 2001; LENCASTRE, 2007b). Se, como agora, pretendermos uma noção abrangente do conceito de marca, que integre a dimensão do sinal de identidade, a dimensão do objeto de marketing a que o sinal se refere, e a dimensão da interpretação que lhe é dada pelos seus públicos, nesse caso optamos pela abordagem triádica (PEREZ, 2004 e 2007; LENCASTRE, 2007a).

Na concepção triádica peirceana, um sinal é qualquer coisa que está no lugar de qualquer coisa para ser interpretada por alguém. Trata-se de uma relação entre três elementos, que nas designações de Peirce são: (1) o "representamen" (o sinal em sentido estrito, ou signo, para recorrer ao termo mais usual na semiótica de língua portuguesa), (2) o "object" (objeto) a que se refere o signo e (3) o "interpretant" (interpretante), que é o efeito que o signo cria na mente de quem o recebe. 
A vantagem da visão triádica da marca na correção da branding myopia é permitir-nos localizar, não apenas uma e a mais evidente forma de miopia, mas as duas outras, mais perigosas porque menos denunciadas, quer na prática quer na literatura de branding. A product branding myopia é a miopia do objeto e a customer branding myopia é a miopia do interpretante. Como os elementos de um sinal estão interrelacionados, incorrer numa é normalmente incorrer nas outras - olhar para o objeto da marca como um produto específico é muito possivelmente olhar para o interpretante da marca apenas como o cliente-tipo desse produto.

\section{Modelo da marca}

Usando como arquétipo a concepção triádica de sinal e integrando nela os diferentes domínios que a prática do branding hoje convoca, podemos conceber um modelo descritivo da marca assente em três pilares fundamentais:

- o pilar da identidade, que engloba o sinal ou conjunto de sinais de identidade da marca - tal como são entendidos na definição jurídica - e das marcas que a ela estão associadas;

- o pilar do objeto, que engloba as diferentes ofertas da marca, bem como a organização e ações de marketing que as suportam;

- o pilar do mercado, que engloba os públicos-alvo e as suas diferentes respostas à marca.

\section{0 pilar da identidade: identity mix e brand mix}

Uma marca, no seu sentido mais estrito de sinal jurídico, é um nome expresso graficamente, uma ortografia. Ao registo do nome podem associar-se outros sinais susceptíveis de proteção jurídica, nomeadamente um logotipo, entendido no sentido de identidade visual associada ao nome ou, ainda, um slogan, um rótulo, uma embalagem, um personagem, um som... O nome, o logotipo e os restantes sinais da sua identidade jurídica compõem o que designaremos por identity mix da marca.

O conceito de identity mix foi pioneiramente utilizado por Olins (1989), não para designar os sinais de identidade da marca em sentido estrito, mas para referir quatro facetas da gestão da sua identidade corporativa: as instalações, os produtos, as comunicações (gráficas) e as pessoas. Era a preocupação de um designer em fugir à label branding myopia de considerar uma marca apenas um nome e um logotipo desligados de todo o conteúdo da marca. Esta preocupação de levar a identidade para além dos sinais que juridicamente são ou podem ser a marca faz com que a literatura tenha ampliado sucessivamente o conceito de identidade corporativa à dimensão intangível da própria missão, valores e cultura da organização (SIMÕES, DIBB \& FISK, 2005; MACHADO, 2007) 
UM TRIÂNGULO DA MARCA PARA EVITAR A BRANDING MYOPIA: CONTRIBUIÇÃO SEMIÓTICA PARA UM MODELO

INTEGRADO DE COMPREENSÃO DA MARCA • PAULO DE LENCASTRE • ANA CÔRTE-REAL

Tendo conscientes os restantes pilares semióticos da marca, preferimos reservar este primeiro pilar para a identidade da marca no seu sentido mais comum, até pelo pragmatismo de definir os limites de competência e envolvimento dos profissionais específicos que normalmente a desenvolvem (MOLLERUP, 1997).

Nesse espírito, procuramos assim distinguir três níveis no identity mix:

- a core identity (identidade central), o sinal que a marca apresenta em primeiro lugar e que normalmente, pelo menos na cronologia, é o nome (e.g. CocaCola, Nestlé, Nike, Cruz Vermelha...);

- a actual identity (identidade efetiva), a expressão ou as expressões gráficas, registradas ou registráveis, do nome da marca, nomeadamente a sua ou suas ortografias, e o seu ou seus logotipos (e.g. Cruz Vermelha passa, no nome e no logo, a Crescente Vermelha nos países muçulmanos); no nome da marca podemos distinguir o nome stricto sensus, que é o elemento distintivo por excelência (e.g. Coca e Pepsi, Chanel e Dior), do genérico associado ao nome, e que o enquadra em alguma parte do objeto da marca (categoria de produtos, local da organização... e.g. Cola, Paris); no logotipo devemos distinguir o lettering (o logotipo em sentido estrito, a sua parte escritural: e.g. a caligrafia ondulante da Coca Cola, o $\mathrm{N}$ cobrindo o restante lettering da Nestlé), o drawing (uma eventual parte desenhada que acompanha o lettering: e.g. o ninho da Nestlé), e o coloring (o código cromático do logotipo: e.g. vermelho e branco da Coca-Cola);

- a enlarged identity (identidade ampliada), todos os outros sinais de identidade da marca susceptíveis de proteção jurídica (um slogan como "Just do it", uma garrafa diferenciada, um personagem como o palhaço Ronald McDonald, um som como o piar do Famous Grouse...), bem como a forma como a marca regulamenta a sua utilização (manual de identidade corporativa).

As marcas que de alguma forma a ela estão associadas quando a estrutura de identidade corporativa da organização cria mais que uma marca, ou ainda as marcas a que a marca se associa em co-branding, compõem o que designaremos por brand mix da marca.

Um brand mix deixa de ser singular quando em sua identidade efetiva se detecta uma variante total ou parcial do nome stricto sensus (e não apenas do genérico: e.g. Nescafé e Nescau em vez de Nestlé Café e Nestlé Cacau) e/ou do logotipo (em seu lettering, drawing e/ou coloring: e.g. o caso dos logotipos diferentes da Nestlé para laticínios e para chocolates) que remete para um produto específico ou um público específico. Num continuum, poderemos distinguir estruturas de identidade monolíticas - de uma só marca - e estruturas de identidade menos ou mais diferenciadas, com menos ou mais marcas cobertas, mais ou menos dependentes da marca de cobertura (OLINS, 1989). 
UM TRIÂNGULO DA MARCA PARA EVITAR A BRANDING MYOPIA: CONTRIBUIÇÃO SEMIÓTICA PARA UM MODELO INTEGRADO DE COMPREENSÃO DA MARCA • PAULO DE LENCASTRE • ANA CÔRTE-REAL

\section{0 pilar do objeto: marketing mix e product mix}

O objeto da marca é, em primeira instância, a organização ou, em termos mais amplos, a pessoa física ou jurídica que o nome da marca identifica. É de seguida a forma como a organização se desdobra em diferentes produtos (produto entendido no sentido lato de uma relação de troca proposta a um público-alvo). É, finalmente, para cada um desses produtos, o conjunto de ações que favorecem a sua venda/troca nos mercados a que se dirigem (marketing mix).

KOTLER (1967) modelizou a ação de marketing em torno de quatro variáveis, os clássicos 4 Ps do marketing mix - product, price, place e promotion. E, na esteira de Levitt, corrigiu a marketing myopia visualizando a variável product num círculo de três níveis concêntricos, sendo o central o "core benefit or service". Segue-se-lhe o actual product, no qual o benefício é tangibilizado em variáveis como a tecnologia, a gama de variantes, o design, a qualidade, a embalagem... e - incorrendo na product branding myopia - a marca. O terceiro nível, que designa por produto ampliado, corresponde aos serviços adicionais que acompanham normalmente a oferta, já com ramificações para as outras variáveis do marketing mix: refere, por exemplo, a entrega, a instalação ou o serviço pós-venda, facetas ligadas à variável place; ou as condições de pagamento, que são parte integrante da variável price.

Esse modelo de base foi sendo ampliado ao longo dos anos, nomeadamente pela criação de novos Ps adaptados a situações específicas. É o caso, por exemplo, em marketing de serviços, em que se fala com pertinência de Ps adicionais como o process e o people, dado o papel preponderante do modo de fazer e de quem o faz na tangibilização de um produto que é intangível (BATESON, 1979).

O marketing mix de um produto pode, assim, ser normativizado como uma série de níveis concêntricos de ações de marketing, desenvolvidas em torno do produto central, que é sempre um benefício, visando a sua tangibilização e a sua colocação no mercado. 
UM TRIÂNGULO DA MARCA PARA EVITAR A BRANDING MYOPIA: CONTRIBUIÇÃO SEMIÓTICA PARA UM MODELO

INTEGRADO DE COMPREENSÃO DA MARCA • PAULO DE LENCASTRE • ANA CÔRTE-REAL

Inspirados nesse histórico, e passando ao registro semiótico triádico que nos orienta nesta análise descritiva da marca, propomo-nos distinguir três níveis no marketing mix da marca:

- o core product (produto central), ou seja a parte do seu objeto que a marca apresenta em primeiro lugar; pode ser uma das suas instalações, um dos seus dos produtos, ou um benefício dirigido a um público-alvo específico (normalmente os clientes, proposta de Levitt para fugir à marketing myopia), ou uma pessoa, ou uma missão diferenciadora que abranja todas as nossas ofertas (de forma a corrigir a product branding myopia: e.g. Volkswagen: resistência; Bic: descartável);

- o actual product (produto efetivo) corresponde às atividades em que a marca se desdobra, o que normalmente é designado na literatura de marketing pela variável "produto", o primeiro "P" do marketing mix (Volkswagen: automóveis; Bic: canetas, isqueiros, aparelhos de barbear...);

- o enlarged product (produto ampliado) corresponde a todas as ações que suportam as trocas da marca, desde a organização, aos processos, às pessoas... aos outros Ps do marketing mix, que variam consoante se trate do marketing dos clientes (o clássico marketing dos Ps de Kotler), dos fornecedores, dos colaboradores, dos acionistas... - a gestão das relações com cada público-alvo tem um marketing mix específico.

Todas as marcas têm, assim, como produto efetivo, um product mix que corresponde ao conjunto das relações de troca que assumem com cada um dos seus diferentes públicos. Quando normalmente se fala de marcas com um só produto (por oposição a marcas estendidas a vários produtos), tal significa que estamos a olhar para a marca apenas na perspectiva do cliente (sintoma de customer branding myopia), não considerando as relações de troca que a marca assume com outros públicos. Na verdade, o que se passa é que, junto de cada público, o product mix da marca pode ser mais ou menos extenso, consoante a marca se apresente com uma ou mais ofertas.

A pluralidade natural, podemos dizer anatômica, do product mix de qualquer marca, levanta o problema da unidade do seu objeto, e da preocupação de algumas marcas se concentrarem em torno de uma missão, um conceito aglutinador dessa multiplicidade que os responsáveis pela marca assumam como razão de existência (KAPFERER, 1992). Ela pode ser expressa das mais diferentes formas na comunicação da marca, desde longos discursos sobre os valores à condensação em torno de uma só frase ou palavra. A diferenciação e perenidade da sua explicitação pode transformar-se em sinal de identidade, caso de slogans particularmente diferenciados e perenes ("Just do it" da Nike), às vezes incorporados no nome da marca (Benetton que passa a ser United Colors of Benetton), ou mesmo nomes e logos que por si só são evocadores, desde a nascença, da missão da marca (Cruz Vermelha, a caridade cristã no sangrento campo de batalha). 
UM TRIÂNGULO DA MARCA PARA EVITAR A BRANDING MYOPIA: CONTRIBUIÇÃO SEMIÓTICA PARA UM MODELO INTEGRADO DE COMPREENSÃO DA MARCA • PAULO DE LENCASTRE • ANA CÔRTE-REAL.

\section{0 pilar do mercado: response mix e public mix}

No conceito de interpretante podemos simplificadamente distinguir duas vertentes: o intérprete e a interpretação. Transpondo para a marca, o interpretante é o mercado - do seu sentido mais restrito ao mais amplo - ou seja a resposta (interpretação) que a marca tem junto de um determinado indivíduo (intérprete), e por extensão junto de um determinado público, entendido como conjunto de pessoas físicas ou jurídicas pertinentes para a marca pela relação de troca que representam. Diferentes públicos (clientes, pessoal, accionistas, fornecedores..., o public mix da marca) terão diferentes reações à marca, porque têm com a organização diferentes relações de troca, e logo têm face a ela diferentes expectativas.

Por sua vez, para cada indivíduo e, estatisticamente, para cada grupo, o conceito de resposta é múltiplo, englobando reações de tipo cognitivo, afetivo e comportamental que se traduzem em variáveis como associações à marca, notoriedade, preferência, compra, fidelidade, para apenas citar as mais frequentemente utilizadas, e que constituem no seu conjunto o que designaremos por response mix da marca.

No response mix da marca podemos assim distinguir:

- a core response (resposta central), é a resposta mais imediata que um indivíduo tem quando é exposto a um sinal da marca; na prática da pesquisa de mercados, será a top of mind das associações à marca, a mais clássica variável de resposta, que podemos designar como posicionamento da marca;

- a actual response (resposta efetiva), é a resposta mais estruturada que o indivíduo pode dar à marca, o seu discurso face a ela, incluindo as marcas que lhe aparecem associadas por com ela terem pontos de paridade, e de como delas se distingue via pontos de diferenciação; na prática da pesquisa de mercados, é o domínio do estudo qualitativo das associações à marca, que podemos designar por imagem da marca (KELLER, 1993);

- a enlarged response (resposta ampliada) corresponde a todas as possíveis reações que teoricamente um indivíduo pode ter porque são detectáveis em maior ou menor escala na actual response de indivíduos de um mesmo público da marca; na prática da pesquisa de mercados é o domínio do estudo quantitativo da marca, e tem como output os resultados do tipo notoriedade, preferência, adesão (ou compra em sentido lato), fidelidade, e, no limite, a quantificação do valor da marca (AAKER, 1991; PEDRO, 2007; CÔRTE-REAL, 2007).

Em qualquer um dos três níveis, podemos distinguir reações cognitivas, afetivas e comportamentais (LAMBIN, 1986): a reação top of mind de um indivíduo pode ser a enunciação de uma característica (no limite, a do desconhecimento total), ser um juízo mais ou menos favorável/desfavorável, ou expressar uma atitude de mais ou menos adesão/rejeição na relação efetiva com a marca (KELLER, 1993); o mesmo se pode dizer na aná- 
lise de conteúdo do seu discurso e na observação do seu comportamento; é igualmente a segmentação clássica quando se transpõem para inquérito os resultados da fase qualitativa, usando associações de tipo cognitivo (produtos: que marcas de produto " $\mathrm{x}$ " conhece?), afetivo (qualidades: a que marcas associa a qualidade "y"?) ou comportamental (relações efetivas: que marcas compra/fornece/investe/ adere?) para avaliar uma marca junto de um dado indivíduo, e, por estatística, junto de uma dada população.

\section{0 triângulo da marca}

A figura 1 sintetiza o que ficou dito num modelo de fácil visualização e compreensão, recorrendo ao triângulo utilizada por Peirce para ilustrar a sua concepção triádica de sinal.

Embora a entrada no modelo possa ser múltipla, a perspectiva do semiólogo é "partir dos sinais para detectar as estratégias" (FLOCH, 2001). Propomos, assim, a sua utilização para uma análise da marca em três fases:

\section{Figura 1}

\section{O Triângulo da Marca}

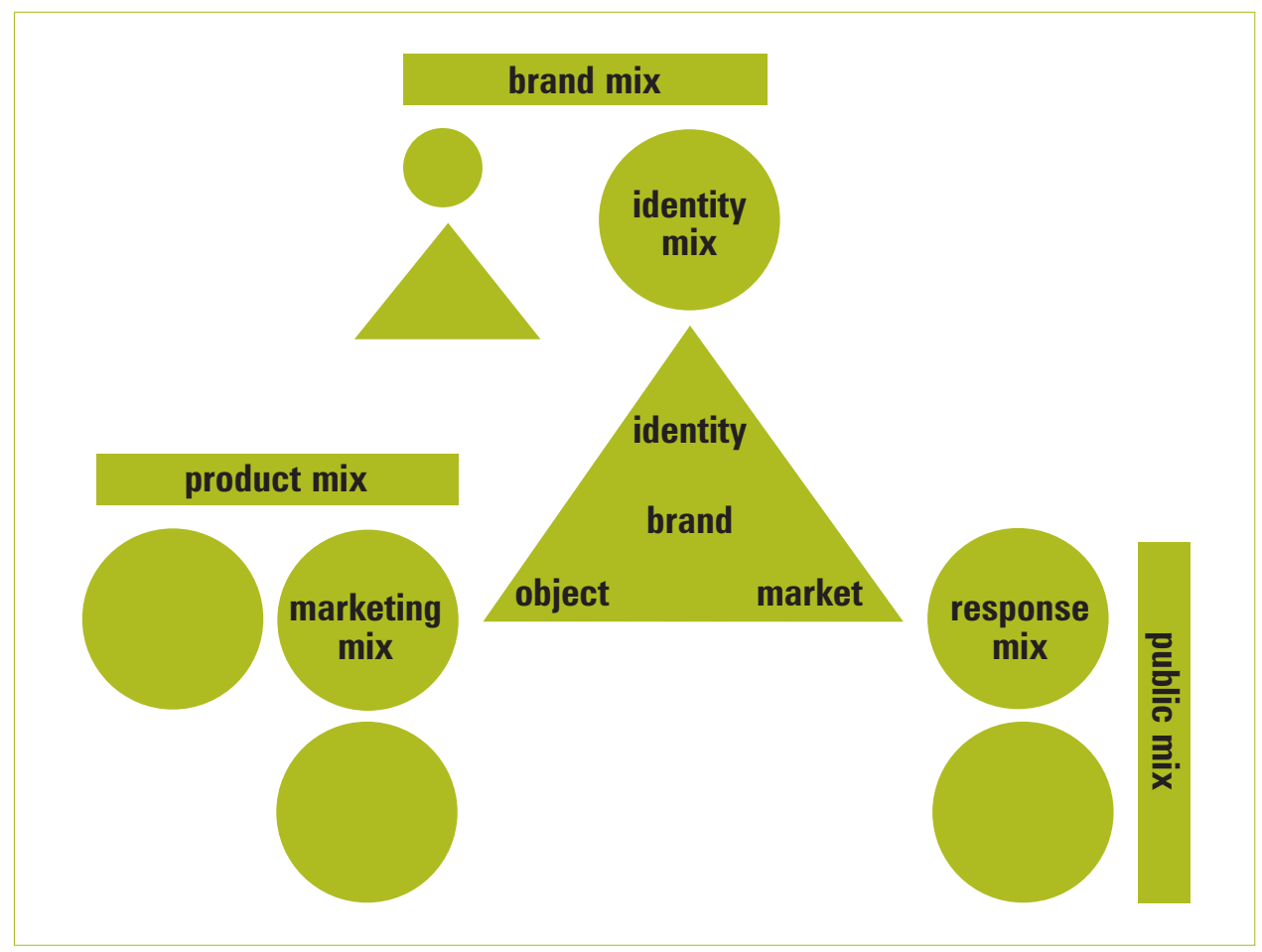




\section{Análise da identidade}

Com base no inventário bruto dos sinais que a organização usa, começamos por verificar se algum ou alguns deles remetem para produtos e / ou públicos específicos, clarificando, assim, se estamos diante de uma identidade corporativa singular ou plural de marcas e de que forma se estrutura (brand mix).

Agrupando por cada marca os seus sinais de identidade (identity mix), distinguimos em seguida como a marca mais imediatamente se denomina (core identity), qual a expressão gráfica completa dessa denominação (actual identity), que outros sinais a ela estão associados e de que forma se conjugam (enlarged identity).

\section{Análise do objeto}

Num segundo passo, para cada marca, distinguimos entre o que ela apresenta como objeto central da sua atividade (core product), de como esse objecto se desdobra em múltiplas relações de troca cobertas pela marca, definindo por um lado a sua extensão (product mix) e por outro a sua segmentação por públicos e segmentos-alvo dentro de cada público (public mix).

Numa análise mais fina, podemos identificar, em cada relação de troca, as ações que do lado da oferta a suportam (marketing mix), distinguindo entre a efetivação do objeto da marca num produto específico (actual product) e todas as ações que o acompanham (enlarged product).

\section{Análise do mercado}

Identificados que foram já, pela via das relações de troca, os públicos e segmentos-alvo da marca (public mix), trata-se agora de conhecer os seus diferentes tipos de resposta (response mix).

A resposta à marca é, antes de tudo, a estatística das associações top of mind que definem o posicionamento (core response) junto de um dado público ou segmento-alvo. São depois todas as associações detectadas espontaneamente em estudo qualitativo, quantificadas em sondagem e expressas graficamente em mapas perceptuais, obtendo-se a imagem da marca face às suas concorrentes (actual response). São finalmente todas as respostas quantificadas à marca decorrentes dessa imagem e que, conjugadas em modelos de avaliação de marcas, estabelecem o valor da marca (enlarged response). 
UM TRIÂNGULO DA MARCA PARA EVITAR A BRANDING MYOPIA: CONTRIBUIÇÃO SEMIÓTICA PARA UM MODELO

INTEGRADO DE COMPREENSÃO DA MARCA • PAULO DE LENCASTRE • ANA CÔRTE-REAL

\section{Conclusão}

O modelo proposto é um modelo descritivo da marca. Permite visualizar de forma simples as suas facetas, integrando-as. Não tem, de início, vocação de prescrição, está a montante, como a anatomia estará para a medicina. A sua única vantagem terapêutica é não perder de vista nenhuma parte do todo, evitar diferentes formas possíveis de miopia da marca.

Com relação à sua aplicação ao management, o modelo permite, antes de mais, olhar a marca como conceito integrador de todas as ações marketing da organização. E, no limite, permite perceber como é reducionista olhar para a marca como mais um ativo intangível da organização, em vez de olhar para a organização como um ativo tangível da marca. Por isso o brand manager é por definição o CEO, o detentor do poder máximo de gestão em cada momento, que conta com stakeholders de diversa natureza (diferentes relações de troca com a organização) para assegurar a vida da marca. Ele próprio, e os que o acompanhem mais de perto, são stakeholders da marca, detentores de um poder transitório. O poder passa, a organização muda, a marca fica... (não será de branding myopia que sofreram/sofrem alguns grandes ditadores da história?).

\section{Referências}

AAKER, David A. Managing brand equity: capitalizing on the value of a brand name. New York: The Free Press, 1991.

ALEXANDER, Ralph S. Marketing definitions: a glossary of marketing terms. Chicago: American Marketing Association, 1960.

BATESON, John E. G. Why we need service marketing. In FERRELL, O. C.; BROWN Stephen. W.; and LAMB, Charles W. (eds.). Conceptual and theoretical developments in marketing. Chicago: American Marketing Association, 1979, p.131-146.

COMUNIDADE EUROPÉIA. Regulamento (CE) n 40/94 do Conselho, de 20 de Dezembro de 1993, sobre a Marca Comunitária, Jornal Oficial, L 011 (14.1.1994), p. 1-36.

CÔRTE-REAL, Ana. 0 valor da marca: análise de um caso paradoxal. In LENCASTRE, Paulo de (org.). 0 livro da marca. Lisboa: Dom Quixote, 2007, p. 301-328.

D'ELBOUX, Sonia. A proteç̧ão legal das marcas no brasil. In LENCASTRE, Paulo de (org.). O livro da marca. Lisboa: Dom Quixote, 2007, p. 101-115.

FLOCH, Jean-Marie. Semiotics, marketing and communication: beneath the signs, the strategies. Houdmills: Palgrave, 2001.

KAPFERER, Jean N. Strategic brand management. London: Koogan Page, 1992.

KELLER, Kevin L. Strategic brand management: building, measuring and managing brand equity. Upper Saddle River: PrenticeHall, 2008.

KELLER, Kevin L. Conceptualizing, measuring, and managing customer-based brand equity. Journal of Marketing, 57 (1), 1993, p. 1-22. 
UM TRIÂNGULO DA MARCA PARA EVITAR A BRANDING MYOPIA: CONTRIBUIÇÃO SEMIÓTICA PARA UM MODELO INTEGRADO DE COMPREENSÃO DA MARCA • PAULO DE LENCASTRE • ANA CÔRTE-REAL

KOTLER, Philip. Marketing management: analysis, planning, and control. Englewood Cliffs: Prentice Hall, 1967.

LAMBIN, Jean J. Le marketing stratégique: fondements, méthodes et applications. Paris: McGraw-Hill, 1986. Trad. portuguesa: Marketing estratégico. Amadora: McGraw-Hill, 2000.

LENCASTRE, Paulo de. A marca: o sinal, a missão e a imagem. In LENCASTRE, Paulo de (org.). 0 livro da marca. Lisboa: Dom Quixote, 2007a, p. 23-71.

LENCASTRE, Paulo de. A figuratividade do nome e do logotipo. In LENCASTRE, Paulo de (org.). 0 livro da marca. Lisboa: Dom Quixote, 2007b, p. 167-211.

LEVITT, Theodore. Marketing myopia. Harvard Business Review, 38 (July-August), 1960, p. 24-47.

MACHAD0, Joana C. A identidade da marca. In LENCASTRE, Paulo de (org.). 0 livro da marca. Lisboa: Dom Quixote, 2007, p. 213-262.

MENDES, Manuel Oehen. 0 direito de marcas no paradigma comunitário europeu. In LENCASTRE, Paulo de (org.). 0 livro da marca. Lisboa: Dom Quixote, 2007, p. 75-100.

MICK, David G. Consumer research and semiotics: exploring the morphology of signs, symbols and significance. Journal of Consumer Research, 13, 1986, p. 196-213.

MOLLERUP, Per. Marks of excellence: the history and taxonomy of trademarks. London: Phaidon Press, 1997.

OLINS, Wally. Corporate identity: making business strategy visible through design. London: Thames and Hudson, 1989.

PEDRO, Margarida. 0 valor e as fontes de valor da marca. In LENCASTRE, Paulo de (org.). 0 livro da marca. Lisboa: Dom Quixote, 2007, p. 265-300.

PEIRCE, Charles S. Collected papers (1931-1958). Cambridge: Harvard University Press, 1999.

PEREZ, Clotilde. Semiótica da marca: a abordagem peirciana. In LENCASTRE, Paulo de (org.). 0 livro da marca. Lisboa: Dom Quixote, 2007, p.119-165

PEREZ, Clotilde. Signos da marca. São Paulo: Thompson Learning, 2004.

ROCHA, Ernesto. Aspectos processuais do registo das marcas. In Seminário Marca: aspectos jurídico-económicos, Lisboa: IMPI, 1991, p. 7-22.

SAUSSURE, Ferdinand de (1915-1966). Cours de linguistique générale. Paris: Payot, 1964. Trad. portuguesa: Curso de linguística geral. Lisboa: Dom Quixote, 1999.

SIMÕES, Cláudia; DIBB, Sally \& FISK, Raymond P. Managing corporate identity: an internal perspective. Academy of Marketing Science Journal, 2005, 33(2), p. 153-168. 